\title{
Complement, immunoglobulin and creatine kinase response in black and white males after muscle-damaging exercise
}

\author{
Andrew J McKune (DTech) ${ }^{1}$ \\ Stuart J Semple (DTech) ${ }^{2}$ \\ Lucille L Smith (PhD) ${ }^{3}$ \\ Ahmed A Wadee (PhD) ${ }^{4}$ \\ ${ }^{1}$ Discipline of Sport Science, School of Physiotherapy, Sport Science and Optometry, University of KwaZulu-Natal, Durban \\ ${ }^{2}$ Faculty of Education, Health and Science, Charles Darwin University, Darwin, Australia \\ ${ }^{3}$ Department of Sport, Rehabilitation and Dental Sciences, Tshwane University of Technology, Pretoria \\ ${ }^{4}$ Department of Immunology, University of the Witwatersrand, Johannesburg
}

\begin{abstract}
Objectives. To determine the effect of eccentrically biased exercise and ethnic group on circulating levels of complement, immunoglobulin creatine kinase. Seven black and 8 white males (18 -22 years), active but untrained, participated in the study. Subjects performed a 60-minute downhill run on a treadmill (gradient $-13.5 \%$ ) at a speed eliciting $75 \%$ of their $\mathrm{VO}_{2}$ peak on a level grade. Venipunctures were performed before, immediately after and then at $3,6,9,12,24,48$, and 72 hours afterwards. Plasma creatine kinase $(\mathrm{CK})$ activity, serum complement $(\mathrm{C} 3, \mathrm{C} 4)$ and immunoglobulin (total IgG, IgG1, IgG2, IgG3, IgG4, IgA) concentrations were compared using a repeated measures ANOVA.

Results. There was an interaction $(p=0.0055)$ and ethnic group effect $(p<0.0001)$ for CK activity with consistently higher levels in the black group. CK increased over time after the run, peaking at $12 \mathrm{~h}$ for both groups. C3, C4, total IgG, IgG1, IgG3, and IgA were significantly higher (ethnic group effect, $p<0.001$ ), and IgG2 significantly lower (ethnic group effect, $p<0.001$ ) in the black group. Significantly higher resting concentrations of total IgG $(+21 \%)$, and IgG1 (+32\%) were observed in this group.
\end{abstract}

\section{Correspondence:}

\section{Andrew J McKune}

Discipline of Sport Science

School of Physiotherapy, Sport Science and Optometry

Faculty of Health Sciences

University of KwaZulu-Natal

Private Bag X54001

Durban, 4000

South Africa

Tel.: +27 (0)312607985

Fax: $+27(0) 312607903$

Cell: $+27(0) 837155683$

E-mail: mckunea@ukzn.ac.za
Conclusions. CK was significantly elevated in the black group although the relative response to exercise in whites was higher, suggesting greater muscle damage. Differences in the concentration of complement proteins and immunoglobulins suggest a heightened immunological/inflammatory milieu in the circulation of the black group. The performance and health implications of this finding warrant further investigation.

\section{Introduction}

Racial disparities have been demonstrated in athletic performance ${ }^{1}$ and in the predisposition towards specific diseases. ${ }^{2}$ Immune/inflammatory pathways may be important in the pattern and/or progression of disease. ${ }^{3,4}$ Research has demonstrated differences in the level of circulating immune/inflammatory markers as well as genotypic differences which may help to explain disease predisposition in specific racial groups. ${ }^{3,4}$ In contrast, there is limited information relating to immune/inflammatory responses to exercise between racial groups. Such information is particularly relevant - strenuous exercise has been shown to alter immune/inflammatory responses predisposing athletes to infection and possibly injury, ${ }^{5}$ which would ultimately impact on training and performance.

Eccentric and/or strenuous unaccustomed exercise has been shown to elicit changes in skeletal muscle morphology. ${ }^{6}$ These changes are typically accompanied by increases in circulating creatine kinase (CK), local muscle swelling and soreness as well as alterations in circulating inflammatory markers such as leucocytes and cytokines. ${ }^{7-9}$ Based on these observations, researchers have utilised exercise, particularly eccentrically biased exercise, to induce muscle damage and investigate immune/inflammatory sequelae.

The key components of innate and adaptive immunity are the complement system and immunoglobulins, respectively. The complement system is composed of a number of proteins that are intricately involved in a variety of immune-related functions. Complement has been described as an important role player in cellular activation, chemotaxis, inflammation and clearance of immune complexes. ${ }^{10-12}$ Immunoglobulins are crucial components of humoral immunity, having pathogen neutralisation and 
opsonisation functions that occur during primary and/or secondary antibody responses. They also regulate cellular cytotoxic activity via sensitisation of natural killer cells, phagocytes, and mast cells, ${ }^{10-12}$ and promote inflammatory responses and the clearance of immune complexes via activation of the complement system. ${ }^{10,11}$

Owing to methodological considerations there are inconsistencies within the literature concerning complement and immunoglobulin response to bouts of strenuous exercise. In addition, there is limited information relating to the circulating levels of these proteins in different racial groups at rest as well as in response to strenuous exercise. Therefore, the first aim of this study was to determine if complement proteins and immunoglobulins are elevated in response to exercise-induced muscle damage. Secondly, inducing this form of benign injury provided the opportunity to investigate if black and white males respond differently to exercise-induced muscle damage.

\section{Method}

\section{Participants}

Active, untrained white $(N=8)$ and black $(N=7)$ males participated in the study. Screening to determine each participant's level of activity and training was performed using the FIT (frequency intensity time) index of Kasari. ${ }^{13}$ This index requires that points are allocated depending on the frequency, intensity and time spent performing physical activity per week with scores ranging from 1 (minimum activity) to 100 (training at a high intensity every day of the week). Individuals were included in the study if their FIT index ranged from 8 to 10 . These are individuals who perform a few days of moderate-intensity physical activity per month, with a duration of $20-30$ minutes per session. The white males were from British or Dutch European descent, the two groups accounting for the majority of cultural variation in South Africa. The black participants were assumed to be of Xhosa ethnicity, based on the stated first language reported from both parents. Based on their self-reported medical history questionnaire, participants were excluded from the study if they exhibited any form of lower-extremity disability/injury that may have been exacerbated by physical activity, and if they were on any anti-inflammatory medication. In order to control for acute illness before, during and after the downhill run, which could affect the immune variables measured in the study, participants completed the Wisconsin Upper Respiratory Symptom Survey (WURSS). ${ }^{14}$ The WURSS is a validated, evaluative, illness-specific quality-of-life instrument, designed to assess the negative impact of the common cold. The survey examines the presence and level of severity of 32 upper respiratory tract symptoms such as a runny nose, sneezing, sore throat and cough. The survey was completed every day for a week before the downhill run, on the day of the run, and every day for a week after the run. All the participants signed an informed consent form approved by the Tshwane University of Technology ethics committee.

\section{Body composition}

Height and weight were recorded using a calibrated medical height gauge and balance scale (Detecto, Webb City, USA). A Harpenden skinfold caliper was used for skinfold measurements (7 sites) to assess per cent body fat (Table I) using the Drinkwater-Ross method. $^{15}$

\section{Assessment of $\mathrm{VO}_{2}$ peak and determination of running speeds}

The participants completed three 10-minute treadmill familiarisation runs on 3 separate days before the $\mathrm{VO}_{2}$ peak testing. The standard Bruce protocol was employed to determine $\mathrm{VO}_{2}$ peak oxygen consumption that was measured by breath-by-breath indirect calorimetry. This was recorded using a Cosmed Quark $b^{2}$ metabolic cart (Cosmed SRL, Italy). Ratings of perceived exertion (RPE) were recorded every 3 minutes and heart rate was recorded every minute using a Polar heart rate monitor. The test was considered to be maximal if the participants exhibited two or more of the following: RPE $\geq 19$; respiratory exchange ratio $\geq 1.1$; heart rate within 5 beats. $\min ^{-1}$ of theoretical maximum heart rate (220 - age). Using metabolic equations ${ }^{16}$ a speed was calculated that would elicit $75 \%$ of the participants' $\mathrm{VO}_{2}$ peak on a horizontal surface. This would be the speed that the participants ran during the downhill run. Therefore, each participant ran at the same relative intensity.

\section{Downhill run}

The downhill run was performed 2 weeks after the $\mathrm{VO}_{2}$ peak test. Participants were instructed to ingest a normal mixed diet, to be well hydrated, and to refrain from any strenuous exercise for at least 72 hours before the downhill run. The downhill runs were performed in a randomised order, between $05 \mathrm{~h} 00$ and $11 \mathrm{~h} 00$ over 2 consecutive Saturdays. This ensured that not all the members of each group were tested on the same Saturday. The participants ran in a fasted state (at least 8 hours after final meal). At the start of the run, they warmed up for 5 minutes by running on a level grade at the predetermined speed. The treadmill was then lowered to a $-13.5 \%$ level and participants ran for 60 minutes. They remained in the exercise testing laboratory for 12 hours after the run, and were provided with food and fluid and encouraged to eat and drink water ad libitum.

\section{Biological fluid sampling and processing}

On arriving in the exercise teaching laboratory, participants were required to sit quietly for 10 minutes before the run. A qualified phlebotomist then inserted a venous catheter (22 gauge, $2.2 \mathrm{~cm}$ ), which was kept patent using a diluted heparin/saline solution. A $15 \mathrm{ml}$ blood sample, using 2 Vacutainer draw tubes ( $5 \mathrm{ml}$ EDTA for CK and $10 \mathrm{ml}$ serum separator tubes (SST) for immunoglobulin and complement), was drawn at the following times: before, immediately after (IPE) and

\section{TABLE I. Physical characteristics of the participants (mean \pm SEM)}

\begin{tabular}{|c|c|c|c|}
\hline Variable & White $(N=8)$ & Black $(N=7)$ & Significance \\
\hline Age (yr) & $20 \pm 0.14$ & $22 \pm 0.36$ & $p=0.12$ \\
\hline Height $(\mathrm{cm})$ & $179 \pm 0.7$ & $173 \pm 0.8$ & $p=0.06$ \\
\hline Weight (kg) & $71 \pm 0.6$ & $70 \pm 1.5$ & $p=0.78$ \\
\hline Body fat (\%) & $16 \pm 0.3$ & $16 \pm 0.6$ & $p=0.31$ \\
\hline $\mathrm{VO}_{2}$ peak $\left(\mathrm{ml} \mathrm{kg}^{-1} \cdot \mathrm{min}^{-1}\right)$ & $44.4 \pm 0.4$ & $43.4 \pm 0.4$ & $p=0.50$ \\
\hline
\end{tabular}


at 3, 6, 9 and 12 hours after the run. Subjects were also required to return for further blood draws at 24,48 and 72 hours after the run. At these times a standard antecubital venepuncture was performed, with the same $15 \mathrm{ml}$ blood sample being obtained. Serum was obtained by allowing the serum separator tubes to stand at room temperature for 30 minutes, and then spun down for 10 minutes at $2000 \mathrm{~g}$. Aliquots were frozen at $-80^{\circ} \mathrm{C}$ in $0.5 \mathrm{ml}$ Eppendorf tubes.

\section{Assessment of biological fluids}

\section{Creatine kinase}

CK activity was determined using a Refletron blood analyser, which uses a colorometric assay procedure (Boehringer Mannheim $\mathrm{GmbH}$, Germany). The within-series precision (CV) of the Refletron ranges from $1.8 \%$ to $3.0 \%$, while the day-to-day precision ranges from $2.2 \%$ to $3.0 \%$. EDTA blood $(32 \mu \mathrm{l})$ was pipetted onto a Refletron CK strip (Roche Diagnostics, Indianapolis, USA). The strip was inserted into the Refletron analyser for 30 seconds. Printed results were recorded. If values were $>1500 \mathrm{IU} / \mathrm{I}$ the sample was diluted with equal parts distilled water (as per manufacturer instructions); $32 \mu$ of this mixture was then pipetted onto a strip and re-run immediately. Values of diluted blood were then doubled.

\section{Serum complement and immunoglobulin}

The total serum concentration of C1-esterase inhibitor (C1-INH), C3, $\mathrm{C} 4$, IgA, total IgG and IgG subclasses was quantified using laser nephelometry (Behring Diagnostics, Frankfurt, Germany). Each set of blood specimens from an individual participant (9 samples) was assayed in a single run with a single lot number of reagents and consumables, by a single operator. All samples were analysed in triplicate with the inter- and intra-assay coefficients of variation lower than $1.9 \%$ and $2 \%$, respectively.

\section{Statistical analysis}

Data were analysed using SPSS version 15.0 (SPSS Inc., Chicago, Illinois, USA). A $p$-value $<0.05$ was considered as statistically significant and data are expressed as mean \pm SEM. Physical characteristics were compared between the two groups using $t$-tests. A repeated measures analysis of variance was used to analyse the main effects (ethnic group and time) and the interaction effects (differences between blacks and whites at any time point(s)), for all dependent measures. The Bonferroni post hoc test was used to locate the differences between means when the observed $F$-ratio was statistically significant $(p<0.05)$.

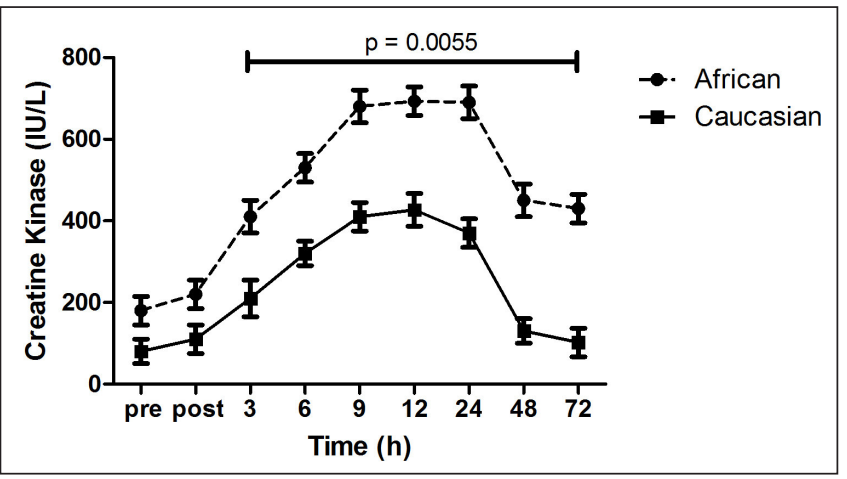

Fig. 1. Total creatine kinase activity for the black and white groups before and at hourly intervals after downhill running. There was a significant interaction effect $(p=0.0055)$, with the creatine kinase in blacks higher from $3 h$ to $72 h$. Values are mean \pm SEM.

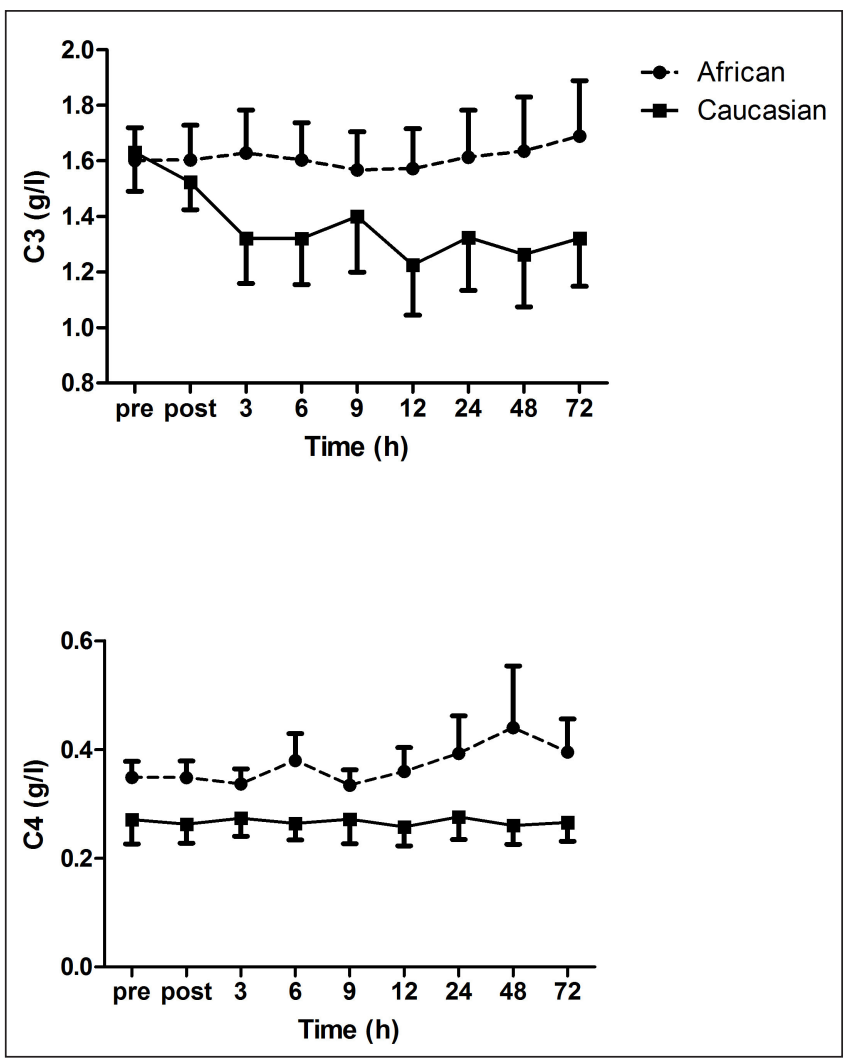

Fig. 2. Serum C3 and C4 for the black and white groups before and at hourly intervals after downhill running. There was a significant ethnic group effect for $C 3(p=0.0018)$ and $C 4(p<0.0001)$, with the means \pm SEM for the black group significantly higher than those for the white group.

\section{Results}

\section{Participant characteristics}

Table I reports the participant characteristics and the maximal exercise test results. There was good matching of the two groups with no significant differences between age, height, weight, body fat percentage or aerobic capacity. There were no reports of symptoms of upper respiratory tract infections throughout the study for both groups.

\section{Serological variables}

All serum complement proteins and immunoglobulin concentrations run were within clinically normal reference ranges. ${ }^{17}$ Statistical results of the different proteins where there were significant differences are discussed individually below. There were no significant alterations in C1-esterase inhibitor and IgG4.

\section{Creatine kinase}

No significant difference in the absolute resting concentration was observed between the black and white groups. There was, however, a significant interaction effect $(p=0.0055)$ after exercise, with absolute levels for the black group higher from $3 \mathrm{~h}$ to $72 \mathrm{~h}$ as determined by the Bonferroni post hoc test $(p<0.01)$. There was an ethnic group effect $(p<0.0001)$, with the black group $98 \%$ higher $(p<0.0001)$. The sum of values (mean \pm SEM) for all time points for the black and white groups was $476 \pm 64 \mathrm{IU} / \mathrm{l}$ and $240 \pm 47 \mathrm{IU} / \mathrm{I}$, respectively. There was also a time effect with significantly $(p<0.001)$ elevated CK levels observed for both groups ( $3-72 \mathrm{~h}$ ), peaking at $12 \mathrm{~h}$ after exercise (black group $=693 \pm 35 \mathrm{IU} / \mathrm{l}$; whites $=427 \pm 40 \mathrm{IU} / \mathrm{l})($ Fig. 1). Although 


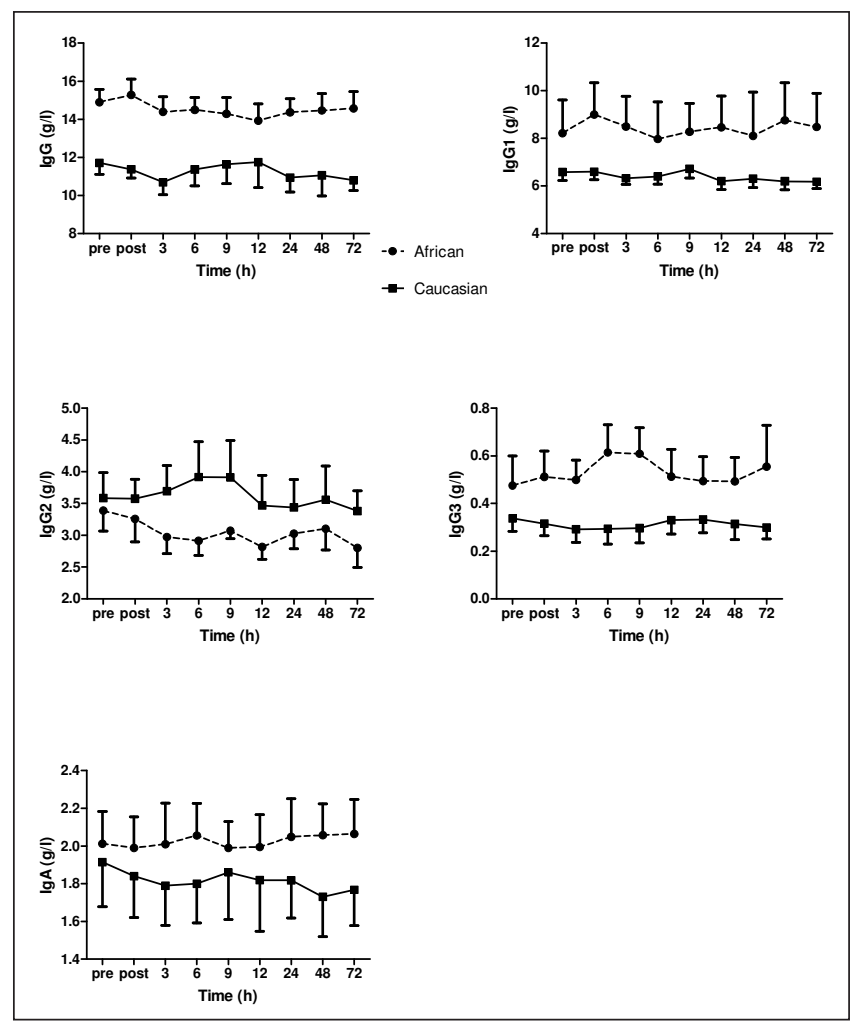

Fig. 3. Serum total IgG, IgG1, IgG2, IgG3 and IgA for the black and white groups before and at hourly intervals after downhill running. There was a significant ethnic group effect, with the means \pm SEM for the black group significantly higher than those for the white group for total IgG ( $p<0.0001), \lg G 1$ ( $p<0.0001)$, $\lg G 3(\mathrm{p}<0.0001)$ and $\lg A(\mathrm{p}<0.033)$, while the white group had higher IgG2 levels $(\mathrm{p}=0.0079)$.

not significantly different, the relative increase from baseline at $12 \mathrm{~h}$ after exercise was $510 \%$ in the white versus $296 \%$ in the black group.

\section{Complement}

\section{C3}

There was no difference in resting C3 concentrations between the two groups. During the 12-hour and 24-hour periods, there was a significant ethnic group effect $(p=0.0018)$, with the mean for the black group $(1.61 \pm 0.01 \mathrm{~g} / \mathrm{l})$ being approximately $17.5 \%$ higher than that for the white group $(1.37 \pm 0.04 \mathrm{~g} / \mathrm{l})$. This difference could be accounted for by the decrease in C3 in whites from IPE $(-7 \%)$ through to $72 \mathrm{~h}$ $(-19 \%)$ after the downhill run compared with baseline. No significant time $(p=0.9)$ or interaction effects $(p=0.9)$ were observed (Fig. 2$)$.

\section{C4}

There was no difference in resting $\mathrm{C} 4$ concentrations between the two groups. During the 12-hour and 24-hour periods, there was a significant ethnic group effect $(p<0.0001)$, with the mean for the black group $(0.37 \pm 0.01 \mathrm{~g} / \mathrm{l})$ approximately $37 \%$ higher than that for the white group $(0.27 \pm 0.002 \mathrm{~g} / \mathrm{l})$. This difference could be accounted for by: (i) an increase in C4 in blacks from $6 \mathrm{~h}(+9 \%)$ to $72 \mathrm{~h}(+13 \%)$, peaking at $48 \mathrm{~h}(+26 \%)$; and (ii) a slight decrease in C4 in whites, with the lowest concentration at $12 \mathrm{~h}(-5 \%)$, after the downhill run. No significant time $(p=0.9)$ or interaction effects $(p=0.9)$ were observed (Fig. 2).

\section{Immunoglobulin}

\section{Total IgG}

There was a significant difference $(p<0.0001)$ in resting total IgG concentrations between the two groups, with the baseline concentrations $21 \%$ higher for the black group compared with the white group. There was a significant ethnic group effect $(p<0.0001)$, with the mean for the black group $(14.52 \pm 0.13 \mathrm{~g} / \mathrm{l})$ approximately $29 \%$ higher than that for the white group $(11.26 \pm 0.13 \mathrm{~g} / \mathrm{l})$. No significant time $(p=0.9)$ or interaction effects $(p=0.9)$ were observed (Fig. 3 ).

\section{lgG1}

There was a significant difference $(p<0.0001)$ in resting lgG1 concentrations between the two groups, with the baseline concentrations $25 \%$ higher for the black group compared with the white group. There was a significant ethnic group effect $(p<0.0001)$, with the mean for the black group $(8.42 \pm 0.11 \mathrm{~g} / \mathrm{l})$ approximately $32 \%$ higher than that for the white group $(6.39 \pm 0.07 \mathrm{~g} / \mathrm{l})$. No significant time $(p=0.9)$ or interaction effects $(p=0.9)$ were observed (Fig. 3$)$.

\section{$\lg G 2$}

There was no difference in resting IgG2 concentrations between the two groups. There was a significant ethnic group effect $(p=0.0079)$, with the mean for the black group $(3.04 \pm 0.06 \mathrm{~g} / \mathrm{l})$ approximately $19 \%$ lower than that for the white group $(3.62 \pm 0.06 \mathrm{~g} / \mathrm{l})$. This difference could be accounted for by: (i) a decrease in IgG2 in blacks, lowest concentration at $72 \mathrm{~h}(-17 \%)$; and (ii) an increase in IgG2 in whites, highest concentration at $9 \mathrm{~h}(+9 \%)$, after the downhill run. No significant time $(p=0.9)$ or interaction effects $(p=0.9)$ were observed (Fig. $3)$.

\section{$\lg G 3$}

There was no difference in resting lgG3 concentrations between the two groups. There was a significant ethnic group effect $(p<0.0001)$, with the mean for the black group $(0.53 \pm 0.02 \mathrm{~g} / \mathrm{l})$ approximately $71 \%$ higher than that for the white group $(0.31 \pm 0.001 \mathrm{~g} / \mathrm{l})$. This difference could be accounted for by: (i) an increase in IgG3 in blacks from IPE $(+8 \%)$ to $72 \mathrm{~h}(+17 \%)$, peaking at $6 \mathrm{~h}(+29 \%)$; and (ii) a decrease in IgG3 in whites from IPE $(-7 \%)$ to $72 \mathrm{~h}(-11 \%)$, lowest concentration at $3 \mathrm{~h}(-14 \%)$, after the downhill run. No significant time $(p=0.9)$ or interaction effects $(p=0.9)$ were observed (Fig. 3 ).

\section{$\lg A$}

There was no difference in resting IgA concentrations between the two groups. There was a significant ethnic group effect $(p<0.033)$, with the mean for the black group $(2.02 \pm 0.01 \mathrm{~g} / \mathrm{l})$ approximately $11 \%$ higher than that for the white group $(1.82 \pm 0.02 \mathrm{~g} / \mathrm{l})$. No significant time $(p=0.9)$ or interaction effects $(p=0.9)$ were observed (Fig. 3 ).

\section{Discussion}

The main finding of the study was that the black group demonstrated consistently higher absolute levels of CK after the downhill run compared with the white group. The results also suggested that there are ethnic differences in the resting and/or post-exercise levels of selected serum complement proteins and immunoglobulins.

The CK result supports previous research examining racial differences in serum CK in South African males. ${ }^{18}$ The differences in absolute CK levels may be attributed to differences in muscle fibre type/distribution and/or lean muscle mass. ${ }^{18}$ However, the white group experienced a greater relative increase (\% change 
from baseline) compared with the black group at $12 \mathrm{~h}$ after exercise. Specifically, there was a $510 \%$ increase in CK in the white group compared with $296 \%$ in the black group. Although this was not significantly different, it may imply that the white group experienced greater muscle damage. This group has been shown to have a lower percentage type Ila fibres, ${ }^{19}$ and type II fibres are more susceptible to exercise-induced damage ${ }^{20}$ and reperfusion injury. ${ }^{21}$ Based on this we would have expected to see higher relative increases in CK in the black group; however, we observed the opposite. Higher resting concentrations of $\mathrm{CK}$ have been attributed to greater lean muscle mass although the literature is conflicting. ${ }^{22}$ This was not measured in the current study and may partly be responsible for the differences observed. Fukashiro et al. ${ }^{23}$ have shown that black athletes have significantly greater muscle viscosity, elasticity and stiffness compared with white athletes. The ability to 'accommodate' greater stress may result in less muscle damage and could possibly explain the lower relative increase in the black group in the current study.

Numerous studies have shown that eccentrically biased exercise may result in the elevation of a number of inflammatory markers. This, and the subsequent pain experienced by the participant, has generally been attributed to muscle damage. While a number of studies have reported a significant elevation in complement proteins after exercise, ${ }^{24,25}$ the current study failed to elicit significant changes in complement $\mathrm{C} 1-\mathrm{INH}, \mathrm{C} 3$ and $\mathrm{C} 4$. This finding was surprising considering that: (i) the participants were untrained; and (ii) research has previously shown that a similar exercise protocol is able to elicit significant elevations in immunoglobulins ${ }^{26}$ and chemotactic cytokines. ${ }^{27}$ In support of our findings, research has documented that certain complement proteins and complement regulatory proteins may not be affected by prolonged strenuous exercise. ${ }^{25,28,29}$ The inconsistent and often conflicting results observed in the literature highlight that a true understanding of the roles of complement proteins in response to exercise requires further elucidation.

Research performed internationally and in South Africa has demonstrated racial/ethnic differences in the reference ranges for serum IgA, IgM, total IgG and IgG sub-classes. ${ }^{30-34}$ Black children and adults tend to have higher values than whites. ${ }^{31-33}$ The results of the current study demonstrate that the black group has significantly higher circulating levels of complement proteins, C3 and C4, as well as immunoglobulin classes and subclasses, IgA, IgG1 and $\lg$ G. $\lg \mathrm{G} 1$ and $\lg \mathrm{G} 3$ are strong activators of the classic pathway of complement, while IgA activates the alternative complement pathway. ${ }^{11}$ IgG2, a weaker activator of complement, ${ }^{11}$ was lower in the black group compared with the white group. In addition, there was no difference in $\operatorname{lgG} 4$, a subclass that does not activate complement. ${ }^{11}$ The elevated complement and immunoglobulin levels suggest a heightened immune/inflammatory milieu in the circulation of black males compared with whites.

Further research is required to determine the factors that may be responsible for racial differences in circulating complement and immunoglobulin. Previous research has suggested that increased exposure to infectious diseases, due to poorer socioeconomic conditions, may play a role in altering immune function in blacks. ${ }^{30,33,34}$ Increased exposure to infectious disease may enhance innate and adaptive immune function, resulting in constitutively higher complement and immunoglobulin levels. However, genetic differences may also be a factor and, together with socio-economic conditions, could shape the development and maturation of innate and adaptive immunity in the black group.

\section{Conclusion}

The white group showed a greater relative increase in CK activity compared with the black group. Although speculative, this may imply that whites are more prone to muscle damage, the effect of which may have implications with regard to how these groups train and adapt to training. The altered complement and immunoglobulin levels in the black group suggest a heightened immune/inflammatory milieu in the circulation. Further research is required to determine the underlying factors responsible for this finding as well as the possible performance and health implications.

\section{REFERENCES}

1. Kohn TA, Essén-Gustavsson B, Myburgh KH. Do skeletal muscle phenotypic characteristics of Xhosa and Caucasian endurance runners differ when matched for training and racing distances? J Appl Physiol 2007;103:932-940.

2. Burchard EG, Ziv E, Coyle N, et al. The importance of race and ethnic background in biomedical research and clinical practice. N Engl J Med 2003;348:1170-1175.

3. Miller MA, Cappuccio FP. Ethnicity and inflammatory pathways -- implications for vascular disease, vascular risk and therapeutic intervention. Curr Med Chem 2007;14:1409-1425.

4. Zabaleta J, Schneider BG, Ryckman K, et al. Ethnic differences in cytokine gene polymorphisms: potential implications for cancer development. Cancer Immunol Immunother 2008;57:107-114.

5. Gleeson M. Immune system adaptation in elite athletes. Curr Opin Clin Nutr Metab Care 2006;9:659-665.

6. Fridén J, Sjöström M, Ekblom B. Myofibrillar damage following intense eccentric exercise in man. Int J Sports Med 1983;4:170-176.

7. Jeukendrup AE, Vet-Joop K, Sturk A, et al. Relationship between gastrointestinal complaints and endotoxaemia, cytokine release and the acutephase reaction during and after a long-distance triathlon in highly trained men. Clin Sci 2000; 98:47-55.

8. Malm C, Sjödin TL, Sjöberg B, et al. Leukocytes, cytokines, growth factors and hormones in human skeletal muscle and blood after uphill or downhill running. J Physiol 2004;556:983-1000.

9. Moldoveanu AI, Shephard RJ, Shek PN. Exercise elevates plasma levels but not gene expression of IL-1beta, IL-6, and TNF-alpha in blood mononuclear cells. J Appl Physiol 2000;89:1499-1504.

10. Janeway CA, Travers $P$, Walport M, Shlomchik M. Immunobiology. The immune system in health and disease. New York: Garland Publishing, 2001.

11. Roitt I, Brostoff J, Male D. Immunology. Edinburgh: Elsevier Science Limited, 2001.

12. Rus $\mathrm{H}$, Cudrici $\mathrm{C}$, Niculescu $\mathrm{F}$. The role of the complement system in innate immunity. Immunol Res 2005;33:103-112.

13. Heyward VH, Stolarczyk LM. Applied body composition assessment. Champaign, IL.: Human Kinetics, 1996.

14. Barrett B, Brown RL, Mundt MP, et al. The Wisconsin Upper Respiratory Symptom Survey is responsive, reliable, and valid. J Clin Epidemiol 2005; 58:609-617

15. Ross WD, Wilson NC. Growth and development. A stratagem for proportional growth assessment. Acta Paediatrica Belgia 1974;24:169-182.

16. Balady GJ, Berra KA, Golding LA, et al. ACSM's guidelines for exercise testing and prescription. Baltimore: Lippincott Williams \& Wilkins, 2000.

17. McKune AJ, Smith LL, Semple SJ, et al. Changes in mucosal and humoral atopic-related markers and immunoglobulins in elite cyclists participating in the Vuelta a Espana. Int J Sports Med 2006;27:560-566.

18. Gledhill RF, Van der Merwe CA, Greyling M, Van Niekerk MM. Race-gender differences in serum creatine kinase activity: a study among South Africans. J Neurol Neurosurg Psychiatry 1988;51:301-304.

19. Ama PF, Simoneau JA, Boulay MR, Serresse O, Thériault G, Bouchard C. Skeletal muscle characteristics in sedentary black and Caucasian males. J Appl Physiol 1986;61:1758-1761.

20. Byrne C, Twist C, Eston R. Neuromuscular function after exercise-induced muscle damage: theoretical and applied implications. Sports Med 2004;34:49-69. 
21. Chan RK, Austen WGJ, Ibrahim S, et al. Reperfusion injury to skeleta muscle affects primarily type II muscle fibers. J Surg Res 2004;122:5460.

22. Brancaccio $P$, Maffulli N, Limongelli FM. Creatine kinase monitoring in sport medicine. Br Med Bull 2007;81-82:209-230.

23. Fukashiro $S$, Abe T, Shibayama A, Brechue WF. Comparison of viscoelastic characteristics in triceps surae between Black and White athletes. Acta Physiol Scand 2002;175:183-187.

24. Dufaux B, Order U. Complement activation after prolonged exercise. Clin Chim Acta 1989;13:45-49.

25. Semple SJ, Smith LL, McKune AJ, et al. Serum concentrations of C reactive protein, alpha1 antitrypsin, and complement (C3, C4, C1 esterase inhibitor) before and during the Vuelta a España. Br J Sports Med 2006;40:124-127.

26. McKune AJ, Smith LL, Semple SJ, Mokethwa B, Wadee AA. Immu noglobulin responses to a repeated bout of downhill running. Br J Sports Med 2006;40:844-849.

27. Smith LL, McKune AJ, Semple SJ, Sibanda E, Steel H, Anderson R. Changes in serum cytokines after repeated bouts of downhill running Appl Physiol Nutr Metab 2007;32:233-240.
28. Fallon KE. The acute phase response and exercise: the ultramarathon as prototype exercise. Clin J Sport Med 2001;11:38-43.

29. Simpson RJ, Florida-James GD, Whyte GP, et al. The effects of marathon running on expression of the complement regulatory proteins CD55 (DAF) and CD59 (MACIF) on red blood cells. Eur J Appl Physiol 2007;99:201-204.

30. Milner LV, Calitz F. Serum immunoglobulin levels in White, Asiatic and Bantu blood donors. S Afr Med J 1971;45:683-685

31. Pieters $\mathrm{H}$, Brand $\mathrm{CE}$, Badenhorst PN, Hendricks ML. Immunoglobulin G sub-class concentrations in South African adults: ethnic differences and reference ranges. Br J Biomed Sci 1997;54:104-109.

32. Ritchie RF, Palomaki GE, Neveux LM, Navolotskaia O. Reference distributions for immunoglobulins A, G, and M: a comparison of a large cohort to the world's literature. J Clin Lab Anal 1998;12:371-377.

33. Roode $\mathrm{H}$. Serum immunoglobulin values in white and black South African pre-school children. Part I: Healthy children. J Trop Pediatr 1980;26:104107.

34. Shulman G, Gilich GC, Andrew MJ. Serum immunoglobulins G, A and M in White and Black adults on the Witwatersrand. S Afr Med J 1975;49:11601164. 